\title{
SCORM e portabilidade: motivação e possibilidades
}

\author{
Liane Margarida Rockenbach Tarouco, PGIE/UFRGS, liane.tarouco@ufrgs.br \\ Renato Luis de Souza Dutra, PGIE/UFRGS, \\ Barbara Gorziza Ávila, CINTED/UFRGS, \\ Anita Raquel da Silva Grando, CINTED/UFRGS,
}

\begin{abstract}
Resumo
O surgimento de ambientes virtuais de aprendizagem comerciais e baseados em software livre que dispõem de interface SCORM aponta para a necessidade de investigar as funcionalidades e possibilidades das soluções de "scormização" existentes nas ferramentas de autorias mais populares em nosso meio. Neste sentido, este artigo buscar trazer como contribuição a este assunto um comentário sobre algumas soluções de integração entre conteúdos "scormizados" e ambientes virtuais de aprendizagem que permitem importá-los.
\end{abstract}

Palavras-chave: SCORM, avaliação formativa, portabilidade

\begin{abstract}
Emergence of SCORM interface in Learning Management Systems either commercial or open software points for the need of research functionality and possibilities of solutions available in popular authoring tools for "scormization". This paper aims to offer as a contribution to this issue a comment about some of the solutions for SCORM content integration in learning management systems.
\end{abstract}

Key words: SCORM, formative evaluation, portability

\section{Introdução}

A tecnologia de informática e comunicação atualmente permite criar material educacional digital usando multimídia com interatividade que torna mais efetivos os ambientes de ensino-aprendizagem apoiados na Tecnologia de Informação e Comunicação. (TIC). No entanto, o projeto e desenvolvimento desses recursos, mesmo considerando o uso de modernas ferramentas de autoria, demandam um complexo arranjo de habilidades multidisciplinares, muito esforço, envolvendo grandes investimentos em recursos humanos e financeiros. Isto levou ao desenvolvimento da estratégia de orientar sua construção com base na metodologia orientada a objetos.

A orientação a objetos, também conhecida como Programação Orientada a Objetos (POO) é um paradigma de análise, projeto e programação de sistemas de software baseado na composição e interação entre diversas unidades de software, denominados de objetos.

Esta metodologia de desenvolvimento orientado a objetos tem sido amplamente utilizada no desenvolvimento de software. Durante anos, os programadores se dedicaram a construir aplicações por vezes muito parecidas com outras que já tinham sido anteriormente produzidas e que resolviam problemas ligeiramente diferentes. Para conseguir que os esforços dos programadores pudessem ser utilizados por outras pessoas foi criada a Programação Orientada a Objetos. Esta inclui uma série de normas de realizar as coisas de maneira com que outras pessoas possam utilizar o que já foi feito e progredir a partir daquele ponto sem precisar começar sempre "do zero". Usando 
normas e padrões para nortear o desenvolvimento do trabalho, são asseguradas melhores condições para que o código desenvolvido possa ser reutilizado.

Analogamente, os objetos de aprendizagem surgiram como forma de organizar e estruturar materiais educacionais digitais tendo em vista sua reusabilidade. A reusabilidade pressupõe também a existência de um sistema de catalogação de objetos de aprendizagem com vistas a assegurar acessibilidade, pela possibilidade de acessar recursos educacionais em um local remoto e usá-los em muitos outros locais. Um primeiro passo neste sentido foi dado com a implantação de um repositório de objetos de aprendizagem (Tarouco 2003) catalogados com meta dados derivados do padrão ISSO/IED LOM (ISSO/IEC 2003). Este repositório, denominado CESTA - Coletânea de Entidades de Suporte ao uso de Tecnologia na Aprendizagem tem crescido com a adição de novos recursos mas o uso de tais recursos tem sido através de links em páginas com material de apoio que apontam para os recursos. Quando os recursos apontados tem itens com interatividade, o resultado desta interatividade fica restrito ao objeto de aprendizagem em si não havendo integração ou registro do resultado da interatividade no ambiente virtual de aprendizagem eventualmente utilizado para apoiar a atividade de ensino-aprendizagem. Isto leva à necessidade de incluir no ambiente virtual de aprendizagem itens específicos de apoio à avaliação o que demanda apreciável quantidade de trabalho para registro e configuração destes itens que via de regra ficam associados ao ambiente utilizado com pouca ou nenhuma facilidade de importação e exportação deste tipo de material para outros ambientes ou mesmo para uma instalação do mesmo ambiente em outra máquina.

A adoção de padrões abertos para nortear o projeto e desenvolvimento de objetos de aprendizagem com interatividade é desejável, uma vez que o rápido avanço da tecnologia leva à possível substituição de plataformas de gerenciamento de aprendizagem com maior rapidez do que a desatualização e/ou obsolescência de um objeto de aprendizagem, que pode ser atualizado e continuar a ser reusado em outro contexto. A estratégia de adotar padrões abertos também tem como objetivo alcançar independência de plataforma onde os objetos vão ser exibidos/executados permitindo o uso de diferentes sistemas operacionais e plataformas de hardware

Adicionalmente, a reusabilidade implica em considerar aspectos relativos à interoperabilidade, pois para que se possa utilizar componentes desenvolvidos por outros, é preciso que estejam resolvidas, de alguma forma, as maneiras de integrar tais componentes possibilitando passar informações derivadas da execução do componente integrado para serem utilizadas por outro componente e que este componente atenda a requisitos de interfaceamento para repassar os informações derivadas de sua execução para outros componentes e assim sucessivamente. Isto requer algum grau de padronização na especificação destas interfaces para a troca de informações entre os objetos de aprendizagem e o sistema de gerenciamento de aprendizagem (LMS Learning Management System).

A vantagem derivada consiste em aumentar a durabilidade do resultado do esforço de desenvolvimento pois permite continuar usando recursos educacionais, sem extenso reprojeto ou recodificação. Um grande passo foi conseguido nesta direção a partir do momento em que uma iniciativa do governo norte-americano recebeu o apoio da comunidade para dar suporte a um modelo de referência denominado SCORM (Sharable Content Object Reference Model) (ADL 2004). SCORM é um modelo desenvolvido e distribuído pela ADL (Advanced Distributed Learning), cujo objetivo principal é permitir a reusabilidade de material instrucional disponibilizado em cursos à 
distância. SCORM define e descreve um conjunto de normas que especificam tanto os requisitos que o material de aprendizagem sendo executado e usado no lado da estação de trabalho do estudante, possa interagir para receber dados e enviar resultados para o servidor onde está sendo executado um LMS - Learning Management System (no Brasil este componente tem sido denominado AVA - Ambiente Virtual de Aprendizagem).

Este padrão define como os recursos que são a menor unidade física dentro de um material devem ser construídos em conformidade com o SCORM para que possam ser reutilizados em diferentes AVAs. Um recurso reusável tem associado a ele uma série de metadados que permitem catalogá-lo e, posteriormente, procurá-lo e encontrá-lo em repositórios on-line, tal como o CESTA. Exemplos de recursos podem incluir: páginas web, imagens (GIF, JPEG), recursos de áudio (WAV MP3), Objetos em Flash, funções em JavaScript, etc... Além disso são definidos arquivos de declaração destes materiais e como o conjunto deve ser organizado (ou agregado) em um arquivo tipo zip para ser enviado para o AVA onde vai ser descompactado e instalado no ambiente de tal modo que as interações dos estudantes com o material vão poder ser monitoradas, acompanhadas e registradas no ambiente.

O SCORM é na verdade um modelo de referência, ou seja, conjunto unificado de especificações para a disponibilização de conteúdos e serviços de e-learning. Este conjunto de especificações define um modelo de agregação de conteúdo, um modelo de sequienciamento e um ambiente de execução para objetos de aprendizagem (ADL 2004).

Um dos grandes diferenciais para a utilização do SCORM no desenvolvimento de conteúdo para educação à distância é seu foco na reusabilidade, acessibilidade, interoperabilidade e durabilidade. O SCORM tem como um de seus objetivos propiciar a independência de plataforma na qual os objetos serão utilizados, assim como facilitar a migração de cursos entre diferentes LMS que sejam compatíveis com esse modelo. A migração de um curso através de um processo de empacotamento ${ }^{1}$ conforme as especificações do SCORM demanda um esforço reduzido. Além disso, o conteúdo desenvolvido em conformidade com SCORM é independente de contexto, ou seja, funcionará em situações variadas, seja inserido em um ambiente de gerenciamento de aprendizagem ou como parte de um curso on-line publicado diretamente na Web ou ainda em cenário híbrido.

O uso destas soluções recebeu atenção maior no Brasil, a partir do advento da UABUniversidade Aberta do Brasil que tem sido operacionalizada sob a forma de consórcios. Esta organização mediante a organização de parcerias entre universidades torna crucial a questão da portabilidade pois é possível que cada uma das consorciadas utilize um servidor localizado em máquina local, diferente das demais. O ambiente virtual de aprendizagem determinado para a UAB é o Moodle, que já é utilizado por muitas universidades no Brasil. Tendo em vista que o Moodle dispõe de interface que permite receber conteúdo compatível com o SCORM, acredita-se que empacotar os conteúdos educacionais digitais usando este padrão possa facilitar a portabilidade dos conteúdos.

Assim, uma conteúdo pode ser produzido em uma instituição e transportado para o ambiente de outras entidade, com esforços menores de configuração das atividades. Isto é especialmente relevante no caso das atividades e materiais que tem características de interatividade as quais podem ser aproveitadas para acompanhamento do uso de tais

\footnotetext{
${ }^{1}$ Empacotamento de conteúdo é um processo em que o designer instrucional agrega todos os objetos de aprendizagem de uma determinada unidade de aprendizagem em um único local, gerando um arquivo compactado denominado de pacote.
} 
materiais pelos alunos, com registro e contabilização automático, não apenas do acesso aos materiais, como também dos resultados das interações oportunizadas aos estudantes.

Este artigo apresenta inicialmente a motivação para a inclusão de interatividade em materiais educacionais digitais e a seguir aponta alguns exemplos de como isto pode ser implementado utilizando-se ferramentas de autoria bem conhecidas no mercado de produção de material educacional digital. A seguir é descrito como o processo de empacotamento do material segundo o padrão SCORM pode ser utilizado para integrar o resultado do uso destas ferramentas em um AVA que tenha interface SCORM e mais especificamente o caso do Moodle.

\section{Avaliação como motivação para implementar interatividade na educação a distância}

A avaliação do aluno, sempre foi algo que desafiou e estimulou professores, na busca de algo que realmente perceba a real situação do aprendizado do aluno. Ela implica em um coleta sistemática de evidências por meio das quais se possa determinar mudanças que ocorrem nos alunos.

Por outro lado, a avaliação entra como um fator de motivação importante, pois é uma forma de incentivar e estimular o aluno a cumprir o programa, constituindo para o mesmo uma recompensa o fato de completar com êxito uma atividade. Percebe-se em praticamente todos os cursos a distância uma dose de ansiedade dos estudantes por resultados de avaliações e na medida em que as mesmas vão sendo publicadas ocorrem manifestações que permitem avaliar o impacto significativo das mesmas.

É interessante observar que os estudantes sempre buscam atender ao que eles imaginam ser o modelo do aluno para determinado professor. Se um professor informa que observa estatísticas e registros de uso do sistema para ter uma idéia da intensidade e padrão de uso dos recursos que disponibiliza aos alunos constatou-se que alguns alunos até tentam imprimir um padrão de uso acessando os diferentes recursos de aprendizagem. Mas o que muitas vezes se constata é que os alunos sub-utilizam o material educacional elaborado para apoiar seu processo de aprendizagem.

A simples colocação de material à disposição dos estudantes não assegura que os mesmos vão ser aproveitados com eficácia. Uma das causas que esta falta de atenção decorre do fato de que a maioria dos textos não incorporar aprendizagem ativa. Usam apenas instrução unidirecional. O estudante lê o que foi escrito mas não tem meios para manifestar-se. Inexiste interação entre o autor do texto e o estudante. É preciso tornar o texto interessante e vívido e isto se consegue através da interatividade.

O texto deve possibilitar a construção de um diálogo com o estudante. A interatividade com o ambiente de ensino-aprendizagem pode ser alcançada através de testes, autotestes e registros de respostas para os quais ocorre alguma realimentação. A realimentação pode ser proporcionada pelo professor, pode ser gerada mediante o uso de algum sistema de correção automática ou pode ser derivada da observação das respostas dos colegas.

A realimentação/avaliação que o professor fornece deve ser calcada não apenas nas respostas a questões específicas mas deve ser derivada de todo um conjunto de evidências que, no caso de educação a distância utilizam, além das manifestações explícitas dos alunos, os registros de atividade gerados pelo ambiente virtual de 
aprendizagem, ou seja o rastreamento das ações e interações automaticamente gerados pelos ambientes virtuais de aprendizagem.

\section{Rastreando a atividade do aluno de educação a distância}

Busca-se a melhor forma de fazer o rastreamento ou monitoramento do aluno no curso, registrando as interações deste com o ambiente e apresentando estas informações de forma que o professor possa ter uma noção do seu progresso no curso. O rastreamento é importante porque permite ao professor monitorar o progresso dos alunos no curso, registrando cada passo dado, mostrando assim que tipo de acesso o aluno tem feito (unidades visitadas, ferramentas utilizadas, etc), bem como o tempo gasto com o acesso desses.

O mecanismo de rastreamento também é importante, pois pode ser um guia do aluno, em virtude dos recursos que tem utilizado, e das páginas que tem acessado, pode orientá-lo sobre como proceder para ter um melhor aproveitamento do material. No rastreamento tem-se o uso de captura automática das ações do usuário. Com este recurso, o professor deve poder derivar o grau de dificuldade e de interesse de uma determinada unidade e então proceder às devidas alterações para aprimorar ou ajustar o suporte oferecido aos alunos adequando-os à população alvo. Pode também verificar o progresso do aluno e orientá-lo ou prover suporte adicional. É importante que o aluno também tenha acesso a este tipo de informação, para que tenha um acompanhamento de seu próprio progresso. É comum em cursos à distância receber perguntas dos alunos visando assegurar-se de que o que fizeram em determinada atividade era o que eles eram suposto fazer esse o resultado de seu trabalho foi efetivamente recebido e apropriado pelo ambiente virtual de aprendizagem.

Estes mecanismos são especialmente importantes para apoiar a avaliação formativa a qual pode ser entendida como "toda prática de avaliação contínua que pretenda melhorar as aprendizagens em curso, contribuindo para o acompanhamento e orientação durante todo seu processo de formação. É formativa toda a avaliação que ajuda o aluno a aprender e a se desenvolver, que participa da regulação das aprendizagens e do desenvolvimento no sentido de um projeto educativo" (Perrenoud 1999). A avaliação neste novo paradigma deixa de ser apenas um instrumento de verificação da aprendizagem para atuar diretamente no processo de ensino-aprendizagem, de forma contínua, durante todo o processo. Tadavia, como o próprio Perrenoud destaca, dentre as novas competências para ensinar, o professor precisa "apostar em tecnologias e dispositivos didáticos interativos portadores de regulação" e "conseguir fazer com rapidez a triagem de um grande número de observações fugazes para identificar uma Gestalt que guiará sua ação e suas prioridades de intervenção reguladora”.

Conforme destacado por Otsuka (2003) a avaliação formativa tem características informativa e reguladora, ou seja, fornece informações aos dois atores do processo de ensino-aprendizagem: ao professor, que será informado dos efeitos reais de suas ações, podendo regular sua ação pedagógica; e ao aprendiz, que terá oportunidade de tomar consciência de suas dificuldades e, possivelmente, reconhecer e corrigir seus próprios erros. O constante acompanhamento e orientação do processo de aprendizagem, intrínsecos a esta forma de avaliação, contribuem para uma maior motivação dos aprendizes e uma melhor percepção de suas dificuldades. 
De modo geral os sistemas de acompanhamento e apoio à avaliação dos ambientes virtuais de aprendizagem, realizam um registro sistemático das atividades e do desempenho do aluno no curso. Registram o acesso e envolvimento do aluno e do professor em suas atividades típicas: leitura de textos, consulta de bibliografia, resposta a questionamentos ou desafios apresentados como atividade escolar mas respostas a perguntas que permeiam o material oferecidos como suporte usualmente ficam fora deste acompanhamento.

\section{Empacotando materiais educacionais segundo os padrões SCORM}

Existem atualmente no mercado uma ampla gama de ferramentas de autoria utilizadas para produzir material educacional digital para educação a distância. Ferramentas de criação de páginas situam-se no topo da lista dentre as mais utilizadas.

Existem software comerciais e de uso grátis que oferecem suporte para transformar páginas HTML com interatividade em pacotes compatíveis com o padrão SCORM.

Mediante o uso de ferramentas livres tal como o Hot Potatoes que a partir da versão 6.2 passou a oferecer a opção de gerar um pacote "scormizado" (um arquivo "zipado") que pode ser importado em qualquer ambiente virtual de aprendizagem compatível com este padrão internacional.

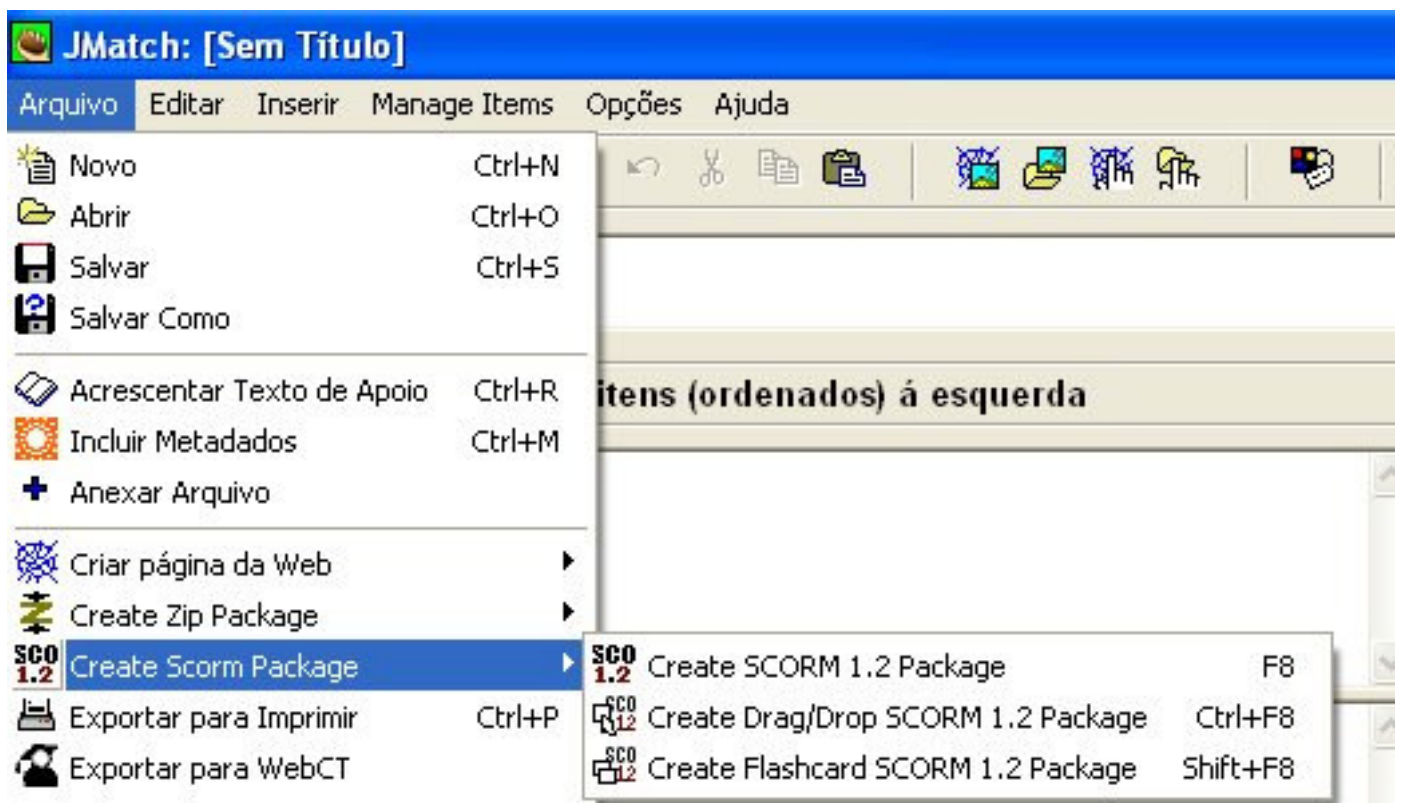

Figura 1: Criando um pacote em formato SCORM como Hotpotatoes

Quando as páginas com exercícios "scormizados" são importadas para o AVA, o uso daquela página será registrado bem como as ações do estudante incluindo o tempo despendido na página com o exercício, o escore obtido ao responder ao que é solicitado no exercício e o modo como ele encerrou o acesso (completou o(s) exercícios, deixou incompleto, time-out etc...) .

Conforme referido por (FCCN 2007) existem no mercado ferramentas para fazer a criação ou adaptar material criado com ferramentas tradicionais de produção de páginas HTML, animações em Flash, apresentações PowerPoint ou mesmo arquivos Word ou Excel. Elas são referidas como ferramentas de autoria e empacotamento e são mostradas na figura 4. 


QuarkXPress + SCORMxt
Adobe (Macromedia) Dreamweaver + L5SCORM
eXe Learning
Macromedia Authorware
Lectora
KnovledgePresenter
Turbo Demo
Macromedia Captivate
Toolbook
Microsoft Word ou PoverPoint + Thesis
Camtasia + PoverPoint Add-in
Sculptoris
Microsoft Office + SCOmaker

Figura 2: Ferramentas de autoria e empacotamento

\section{Importando módulos SCORM}

As principais plataformas comerciais no mercado já oferecem interface SCORM. Podese referir dentre os mais conhecidos o WebCT, Adobe Breeze além de pelo menos uma solução nacional, o AulaNet desenvolvido pela PUC/Rio que oferece uma versão comercial com interface SCORM. Na áreade software livre, a popularização do ambiente Moodle no cenário nacional, o qual dispõe de interface SCORM contribuiu para tornar esta plataforma ainda mais popular.

O Moodle tem um módulo que permite ao professor responsável por um curso fazer o "upload" de um pacote "scormizado". O processo é similar ao de importar qualquer outro recurso (imagem, vídeo, texto etc...), sendo apenas requerido indicar o tipo de atividade (na terminologia do Moodle) a ser incluída, tal como ilustrado na figura 3.

\begin{tabular}{l}
\hline Acrescentar atividade... \\
\hline Acrescentar atividade... \\
Base de dados \\
Chat \\
Escolha \\
Fórum \\
Glossário \\
Laboratório de Avaliação \\
Lição \\
Pesquisa de avaliação \\
Questionário \\
SCORM/AlCC \\
Tarefa \\
Wiki
\end{tabular}

Figura 3: Importando material SCORM
Depois de selecionar a opção de acrescentar atividade do tipo SCORM/AICC será apresentada janela onde será possível indicar o arquivo .zip a ser "uploaded" para o Moodle e uma vez que este arquivo esteja no ambiente poderá ser selecionado como o pacote SCORM a ser incluído no curso como atividade. 
Quando os estudantes utilizam um material importado o sistema permite obter informações tal como as da figura 4.

UFRGS »PIE-0139 »Questionários »Questionários Moodle »Revis ão Atualizar Questionário

\begin{tabular}{|l|l|l|l|}
\hline Info & Resultados & Visualizaçã̃o prévia & Modificar \\
\hline Sinopse & Reavaliação & Avaliaçẫo manual & Análise de item \\
\hline
\end{tabular}

\title{
Revisão da tentativa 2
}

\author{
Tentativas: 1,2 \\ Iniciado em: quarta, 16 maio 2007, 00:55 \\ Completado em: quarta, 16 maio 2007, 00:56 \\ Tempo empregado: 1 minuto 5 segundos \\ Classificaçâo: $7 / 10(70 \%)$
}

Figura 4: Exemplo de registros de atividade importada via módulo SCORM

Adicionalmente o Moodle permite obter informações sobre cada atividade interativa incluída no material, tal como ilustrado na figura 5:

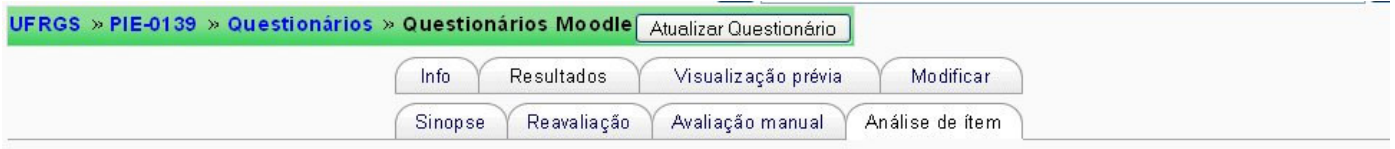

Tabela de análise de itens (3)

\begin{tabular}{|c|c|c|c|c|c|c|c|c|c|}
\hline Q\# - & Texto da questão - & Texto da resposta & $\begin{array}{l}\text { crédito } \\
\text { parcial }=\end{array}$ & $\begin{array}{c}\text { R. } \\
\text { Contagens }\end{array}$ & R.\% & $\begin{array}{l}\% \text { Corretas } \\
\text { Facilidade - }\end{array}$ & $S D=$ & $\begin{array}{l}\text { Disc. } \\
\text { Îndice - }\end{array}$ & $\begin{array}{l}\text { Disc. } \\
\text { Coef. - }\end{array}$ \\
\hline \multirow[t]{4}{*}{$\begin{array}{l}(75) \\
:=Q\end{array}$} & $\begin{array}{l}\text { Exemplo Múltipla } \\
\text { Escolha: } \\
\text { Escute esta música } \\
\text { Que tipo de música } \\
\text { é? }\end{array}$ & Rock & $(0.00)$ & $0 / 9$ & $(0 \%)$ & $56 \%$ & 0.527 & 0.75 & 0.85 \\
\hline & & Jazz & $(1.00)$ & $6 / 9$ & $(67 \%)$ & & & & \\
\hline & & Funk & $(0.00)$ & $0 / 9$ & $(0 \%)$ & & & & \\
\hline & & Samba & $(0.00)$ & $0 / 9$ & $(0 \%)$ & & & & \\
\hline
\end{tabular}

Figura 5: Análise de itens

A combinação destes dois conjuntos de informações constituem realimentação tanto para os alunos como para o professor com vistas a ensejar avaliação formativa. Elas permitem planejar e ajustar situações de ensino-aprendizagem ajustadas ao nível e à realidade do aluno. 


\section{Conclusões}

Com os recursos de autoria e empacotamento compatível com o padrão SCORM os professores poderão produzir externamente módulos de material educacional digital, que contenham opções de interatividade e uma vez que tenham importado este material para um ambiente virtual de aprendizagem poderão dispor de um conjunto apreciável de informações de rastreamento que permitam realizar uma avaliação formativa e realizar tanto a gestão da progressão dos alunos quanto a avaliação da qualidade dos recursos de ensino aprendizagem, a partir da análise dos itens de interatividade utilizados. Se determinados itens constam reiteradamente como não completados pelos estudantes ou mesmo se o resultados da avaliação das respostas pelo sistema indica com frequiência baixo nível de aprendizagem pelos estudantes deriva-se a necessidade de reavaliar o contexto de ensino aprendizagem inicialmente planejado.

A vantagem decorrente do uso de soluções baseadas no padrão SCORM advém da portabilidade do material de ensino-aprendizagem porque embora muitos ambientes virtuais de aprendizagem disponham de ferramentas para criar itens interativos, a forma de seu armazenamento interno no ambiente é proprietária e a exportação dos mesmos para outros ambiente ou mesmo para outros cursos no mesmo ambiente mas em outras máquinas pode demandar trabalho intensivo e repetitivo para entrar com todas as informações relativas aos itens com interatividade em si ou de sua configuração.

Assim, fica facilitado o processo de colaboração entre instituições de ensino que atuam cooperativamente na produção e oferecimento de cursos a distância utilizando ambientes virtuais de aprendizagem instalados em diferentes locais e tem necessidade de portar o material educacional digital para diversos locais.

\section{Referências Bibliográficas}

ADL. Advanced Distributed Learning . SCORM 2004 3rd edition. Version 1.0 Nov 2006.Disponível em: http://www.adlnet.org. Acesso em: 13 mar. 2007.

FCCN - Fundação para a Computação Científica Nacional. Guia de boas práticas sobre SCORM para professores. Disponível em: http://www.fccn.pt/files/documents/GuiaBoasPraticassobreSCORMparaprofessores.pdf Acessado em junho/2007

HotPotatoes. Disponível em: http://hotpot.uvic.ca/ Acesso em Junho de 2007.

IEEE. Draft Standard for Learning Object Metadata. Learning Technology Standards Committee of the IEEE. 2002. Acessível em: http://ltsc.ieee.org/wg12/files/LOM_1484_12_1_v1_Final_Draft.pdf Acesso em: 20 de fevereiro de 2007.

ISO IEC. Final Report on the "International LOM Survey". 2004. Acessível em: http://old.jtc1sc36.org/doc/36N0871.pdf Acesso em 15 de fevereiro de 2007.

Otsuka, Joice. Lacchi, Ricardo. Vahl, José, Rocha, Heloisa. Uso de Agentes de Interface no Ambiente TelEduc. RENOTE. V. 1 No 2, Setembro, 2003

Perrenoud, Philippe. Novas competências para ensinar. Artmed, 1999

Tarouco, Liane. CESTA - Coletânea de Entidades de de Suporte ao uso de Tecnologia na Aprendizagem. 2003. Acessível em: http://www.cinted.ufrgs.br/CESTA/ acessado em 10 de fevereiro de 2007.

Tarouco, Liane. Fabre, Marie, Tamusiunas, Fabrício. Reusabilidade de Objetos Educacionais. RENOTE - Revista Novas Tecnologias na Educação, V1 N1, CINTED/UFRGS, Porto Alegre, 2003. 
